\title{
Recessive metaphyseal dysplasia without hypotrichosis. A syndrome clinically distinct from McKusick cartilage-hair hypoplasia
}

\author{
Alain Verloes, Gerald E Pierard, Martine Le Merrer, Pierre Maroteaux
}

\begin{abstract}
Among children with recessive metaphyseal dysplasia involving the knees and extremities, two types can be distinguished. In true cartilage-hair hypoplasia, as described by McKusick, many patients show clinical hair involvement and variable immunodeficiency. We present a series of six patients with the same radiological changes, but without apparent hypotrichosis. We suggest that they should be considered as having a variant form of cartilage-hair hypoplasia, with a clinically distinct phenotype, which could be as common as 'true' cartilage-hair hypoplasia among non-Amish populations. Microscopic examination of the hair may show reduction in the diameter of the hair shaft. This form of metaphyseal dysplasia may result from allelic heterogeneity.
\end{abstract}

In the early $1960 \mathrm{~s}$, one of us described five children with a metaphyseal chondrodysplasia mainly affecting the bones of the extremities, but sparing the femoral necks, under the name 'forme partielle de la dysostose métaphysaire'. ${ }^{1}$ Two cases had fine, sparse hair together with the typical metaphyseal changes. They were obviously affected with the metaphyseal dysplasia described two years later by McKusick as 'cartilagehair hypoplasia' $(\mathrm{CHH}){ }^{2}$ However, our first three cases (a boy and his two sisters) had perfectly normal

Centre for Human Genetics, Liège University, Belgium. A Verloes

Department of Dermatopathology, Liège University, Belgium.

G E Pierard

Clinique de Génétique Médicale et Unité INSERM U12, Hôpital des Enfants Malades, Paris, France.

$M$ Le Merrer, $P$ Maroteaux

Correspondence to $\mathrm{Dr}$ Verloes, Centre de Génétique Humaine, Pathologie B23, CHU Sart Tilman, B-4000 Liège, Belgium. hair (fig 1), although their bone dysplasia was exactly the same as in $\mathrm{CHH}$.

Since that time, we have had the opportunity to investigate seven other children with a $\mathrm{CHH}$-like bone dysplasia without any clinical hair involvement. We report here three of them, of whom two are sibs.

\section{Case reports}

CASE 1

This boy was born at term to non-consanguineous parents originating from the same village. His father was 26 and his mother 22 years old. Birth weight was $3830 \mathrm{~g}$, length $48 \mathrm{~cm}$. His height fell to less than 2 SD by $2 \frac{1}{2}$ years, and less than $3 S D$ at $81 / 2$ years.

When we first saw him at the age of 10 years 11

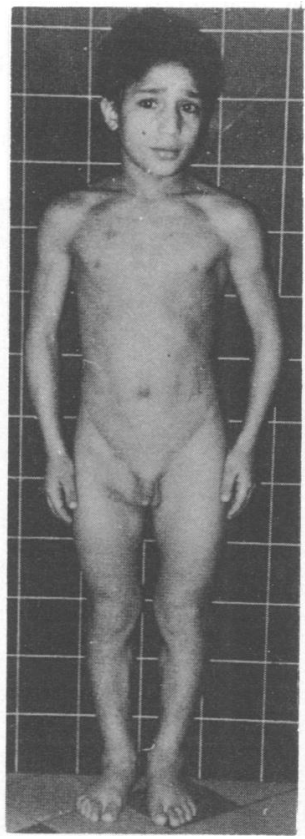

Figure 1 Unpublished picture of the original patient of Maroteaux et al ${ }^{l}$ at 10 years. Slight varus deformity of the legs and normal dark hair. 


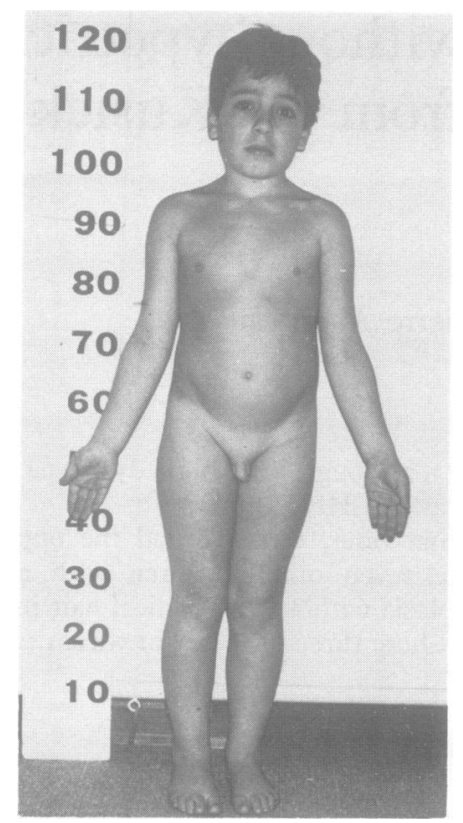

Figure 2 Case 1 at $8^{1 / 2} 2$ years showing dark, thick hair.

months, he was $122.5 \mathrm{~cm}$ tall and weighed $30.5 \mathrm{~kg}$. He had obvious micromelia and short, stubby hands. There was a slight varus deformity of the legs. Joint mobility was not restricted. His hair was dark and thick and growth was normal (fig 2). Calciumphosphorus balance and GH releasing tests gave normal results.

Skull and spine radiographs were strictly normal.

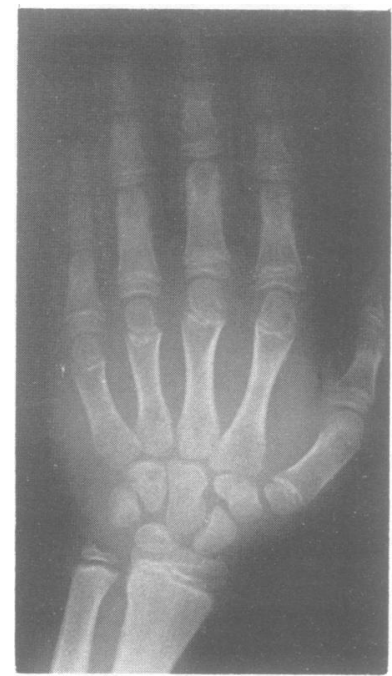

Figure 3 Case 1 at $81 / 2$ years showing slight metaphyseal irregularities and shortened bones.
The long bones were shortened, but the femoral necks $\Phi$ and heads were not affected. The lower femoral $\underset{\sim}{\stackrel{\oplus}{+}}$ metaphyses, upper and lower tibial metaphyses, and

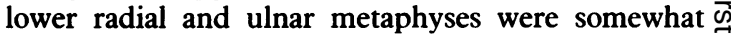
irregular. The bones of the feet and hands were 0 shortened and stubby, with irregular and slightly cupped metaphyses (fig 3). Two brothers were born later and were unaffected.

CASE 2

This girl was born to non-consanguineous, Caucasian parents; her father was 34 and her mother 31 years old. Length was only $45 \mathrm{~cm}$ at term and at 1 year she was $65 \mathrm{~cm}$ tall $(-3 \mathrm{SD})$.

When we saw her at the age of 20 months, she was $73 \mathrm{~cm}$ tall and weighed $9 \cdot 3 \mathrm{~kg}$. She had slight. micromelia and varus deformities of the legs. Her spine was straight and her hair and facies looked normal. She had a café au lait spot, $2 \mathrm{~cm}$ wide, in the middle of her back.

Radiographs showed shortened long bones and severe deformation of the lower femoral metaphyses, which were slightly enlarged, very irregular, and had an inverted V shape (fig 4). Tibial and peroneal metaphyses were similarly affected, as well as the lower extremities of the ulna and cubitus. The pelvis

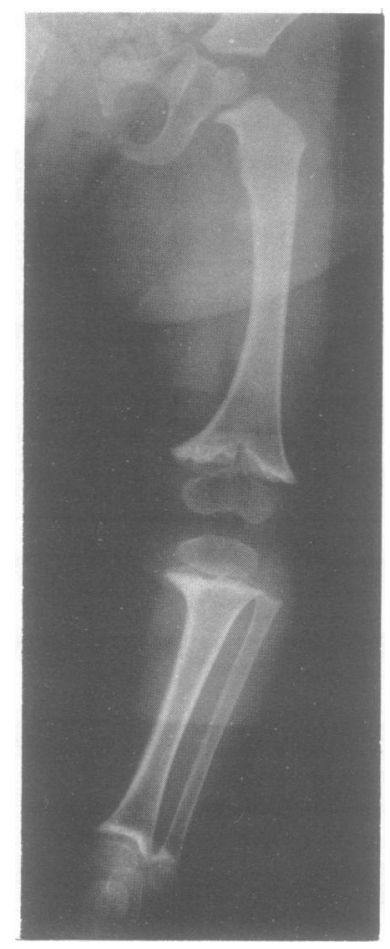

Figure 4 Case 2 at 15 months. Lower metaphysis of the femur and tibial metaphyses are enlarged and very irregular. 


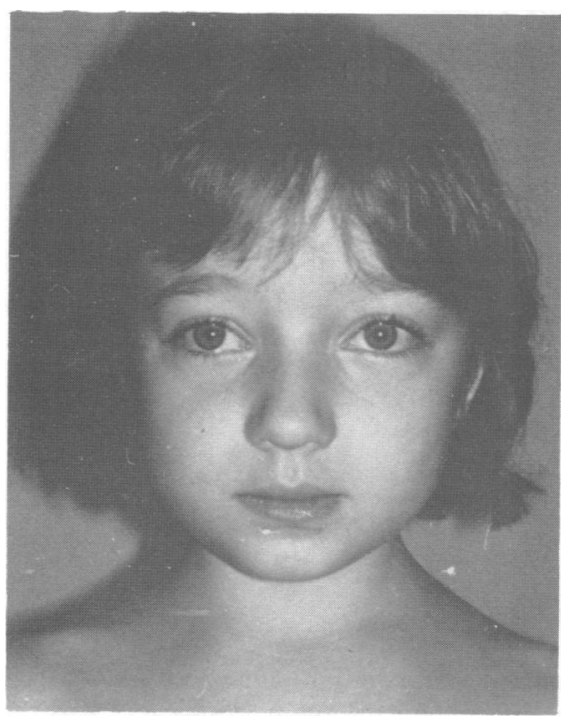

Figure 5 Case 2 at $81 / 2$ years.

femoral neck, and spine were normal. The metaphyses of the hand bones were shortened and concave.

Subsequent follow up was unremarkable. At 8 years 8 months (fig 5), she was an intelligent girl, $110.5 \mathrm{~cm}$ tall $(-3$ to $-4 \mathrm{SD})$, with moderate knock knees. Joint movements were not restricted. Metaphyseal deformities had improved, but irregularities were still severe in the hands, the bones of which were very short and stubby.

Examination of the hair was unremarkable under

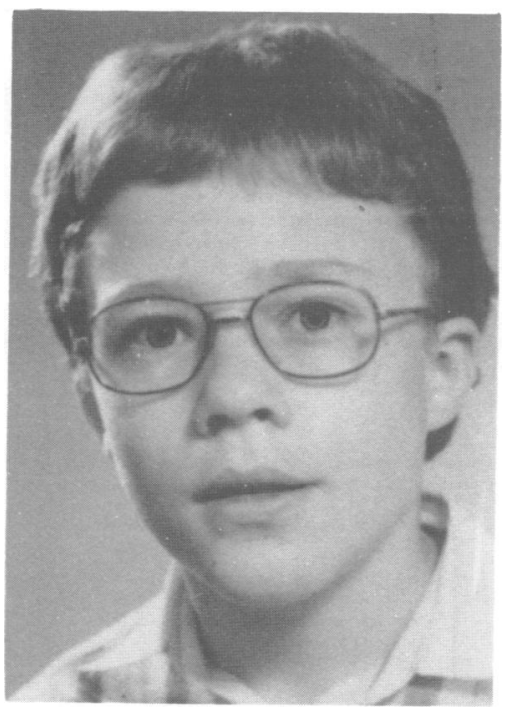

Figure 6 Case 3 at 9 years showing normal hair. normal and polarised light, but the mean hair shaft diameter was abnormal: $33 \cdot 1 \mu \mathrm{m} \pm 11 \cdot 8$ (controls $79 \cdot 2 \mu \mathrm{m} \pm 24 \cdot 5$ between 8 and 12 years).

\section{CASE 3}

Case 3 is the older brother of case 2. He was only 46 $\mathrm{cm}$ long at birth. We first saw him at the age of 4 years 5 months, when the diagnosis of MD was established for his sister. At that time, he was $98 \mathrm{~cm}$ tall (-2 SD) and had normal hair (fig 6). Radiological investigations showed severe metaphyseal alterations, very similar to those observed in his sister. The most prominent changes concerned the lower femora, which had a pseudoenchondromatous appearance (fig 7). The bones of the hand were short and stubby (fig 8 ). We saw him for the last time in 1988, at the age of $11 \frac{1}{2}$ years; he was $142 \cdot 3 \mathrm{~cm}$ tall (mean) and weighed $40 \mathrm{~kg}$. This apparent catch up in height was the result of a slightly premature pubertal growth spurt. The spine and legs were not deformed, but the hands were very short. All the metaphyseal alterations were less striking than during previous examinations.

Examination of hair structure was unremarkable, and the mean shaft diameter was $74.4 \mu \mathrm{m} \pm 22.4$ (normal).

\section{Discussion}

These three cases, three children previously published, and four other unpublished cases from our files show the same pattern of defects. The clinical hallmarks are stunted growth, owing to disproportionate limb shortening, short hands and feet, and normal face and hair. Although moderate dwarfism does exist from birth (birth length 45 to $48 \mathrm{~cm}$ ), diagnosis is usually made later. Growth retardation is usually severe, but intrafamilial variation exists, as illustrated in our cases 2 and 3.

The long bones are shortened. The distinctive radiological features are restricted to the metaphyses close to the knees and to the distal metaphyses of the tibia, ulna, and cubitus. Hand bones are always involved: they are short and stubby, and their metaphyses look concave and irregular. The metaphyseal irregularities are more prominent in the first years, but they fade with time and are not apparent after the disappearance of the growth cartilage. The femoral necks, spine, and pelvis remain unaffected. The metaphyses of the ribs are sometimes enlarged and irregular.

The recurrence of this dysplasia in a sibship with unaffected parents suggests autosomal recessive inheritance, although parental consanguinity has not been observed. Both sexes are equally affected: five boys and five girls in our series.

The general build and radiological features of this metaphyseal dysplasia suggest the diagnosis of 


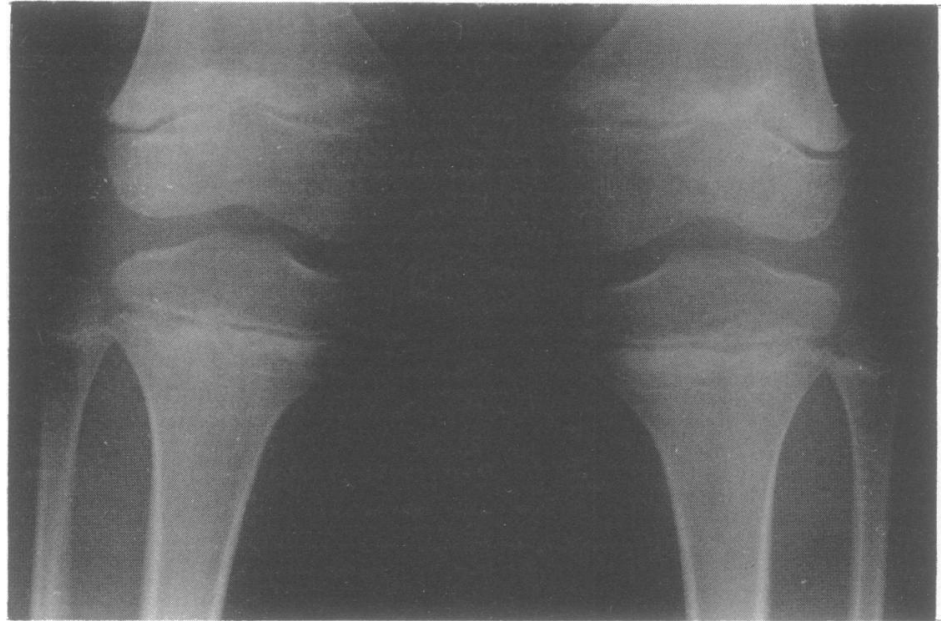

Figure 7 Case 3 at 9 years showing metaphyseal irregularities of the knee.

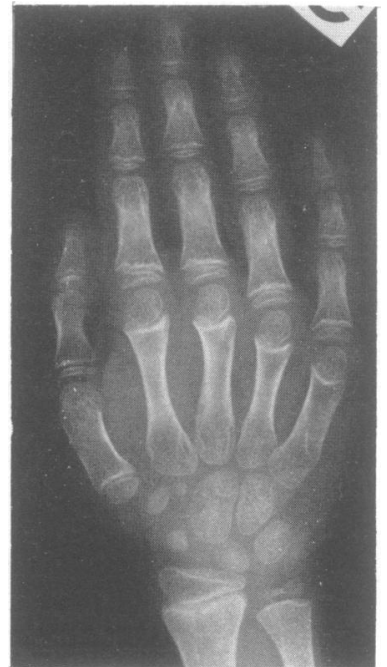

Figure 8 Case 3 at 9 years showing shortness of hand bones with metaphyseal irregularities.

McKusick cartilage-hair hypoplasia. ${ }^{3}$ The major difference is the apparent lack of hair involvement. None of our cases had sparse or fair hair. Nevertheless, measurement of hair diameter showed a significant 옥 reduction in one of them. However, this reduction was less than the diameters given by McKusick $e a^{2}$ : 37 of 37 patients studied had a mean hair diameter between 12 and $34 \mu \mathrm{m}$. None of our 10 patients had immunodeficiency. ${ }^{4}$

Our experience is that this form of MD without clinical hair dysplasia could be almost as common as typical $\mathrm{CHH}$ in non-Amish populations. Linkage studies are required to determine if $\mathrm{CHH}$ an recessive $M D$ are the result of defective expression of genes at distinct loci, or manifestations of allelic heterogeneity for the same gene.

We are very grateful to Dr P Garnier and Professor J C Job for referring case 1 and to Dr Sorin for referring cases 2 and 3.

1 Maroteaux P, Savart P, Lefebvre J, Royer P. Les formes partielles de la dysostose métaphysairc. Presse Med 1963;30 1523-6.

2 McKusick VA, Eldridge R, Hostetler JA, Ruangwit U, Engeland JA. Dwarfism in the Amish. II. Cartilage hair hypoplasia. Bull Johns Hopkins Hosp 1965;116:285-326.

3 Ray HC, Dorst JP. Cartilage-hair hypoplasia. In: Intrinsic diseases of bone. Progress in Pediatric Radiology Vol 4. Basel: Karger, 1973:270-98.

4 Pierce CF, Polmar SH. Lymphocyte dysfunction in cartilage-hair hypoplasia. Evidence for an intrinsic defect in cellular proliferation. F Immunol 1962;129:570-5. 